\title{
Synthesis of Calcium Phosphate Controllable Coating Thickness on Oil-in-Water Nanoemulsion with Performance of Oxygen Release as Oxygen Carrier
}

\author{
Kyu-Bum Han'1, Curtis Takagi', Chun-Jen Wu², Hiroshi Mizukami², Agnes Ostafin ${ }^{2,3}$ \\ ${ }^{1}$ Materials Science and Engineering, University of Utah, Salt Lake City, UT, USA \\ ${ }^{2}$ Nanoshell, Co., Layton, UT, USA \\ ${ }^{3}$ Chemical Engineering, University of Utah, Salt Lake City, UT, USA \\ Email: k.han@utah.edu
}

Received 17 January 2016; accepted 28 March 2016; published 31 March 2016

Copyright (C) 2016 by authors and Scientific Research Publishing Inc.

This work is licensed under the Creative Commons Attribution International License (CC BY).

http://creativecommons.org/licenses/by/4.0/

(c) (i) Open Access

\begin{abstract}
Perfluorocarbon emulsion has been studied as an oxygen carrier, due to its high oxygen content. In clinical trials, it has shown stability in delivering oxygen to the target region. The purpose of the present study was to increase the stability of the emulsion by coating its surface with calcium phosphate. A layer-by-layer method was employed to coat the flexible emulsion surface. Considering the ionic affinity of calcium and phosphate to the lecithin emulsion surface, the first layer of coating was calcium and the second layer was comprised of phosphate ion. The coated emulsion demonstrated various oxygen release times depending on the thickness of the layers: from 0.04 sec. for a thickness of $8 \mathrm{~nm}$ to 0.17 sec. for a thickness $38 \mathrm{~nm}$. Overall, the stability of the calcium phosphate coated emulsion was increased, while its original function as an oxygen carrier was maintained.
\end{abstract}

Keywords

Perfluorocarbon, Calcium Phosphate, Nanoemulsion, Oxygen Carrier, Surface Coating

\section{Introduction}

Artificial oxygen carriers are designed to fulfill the oxygen carrying function normally performed by red blood cells (RBCs). There are, generally, two types of systems studied, hemoglobin and perfluorocarbon (PFC) based, with many developers concentrating on the PFC emulsion [1]-[6]. The efficacy of the emulsion, however, is still 
limited by its poor stability, making it difficult to package as it easily flocculates and coalesces during processsing. Thus, it is important to produce a stable emulsion system that can withstand various processing and storage conditions. This work created a rigid surface that encapsulated the particle with calcium phosphate and performed the encapsulated particle in stability and as an oxygen carrier.

Various materials have been used to the particle surface such as metal core silica, silica, and polymer. Silica has long been utilized as a coating on solid core particles in chemical and biological applications because the reactions on the surface can be easily characterized and the particle is electrostatically stable in an aqueous solution [7]-[9]. The $\mathrm{pH}$ plays an essential role in silica. If the $\mathrm{pH}$ is acidic, silica tends to fuse together and becomes a gel. If the $\mathrm{pH}$ is basic, the particles separate from each other by yielding to the negative surface charge. Additionally, silica resists biodegradation and is only dissolved in a strong base. Silica also has the porosity for reactants to diffuse in and out when it is utilized for the surface coating. These properties have made silica useful in many applications [10] [11], as a biomarker by protecting the fluorescence molecules inside of the particles [12] [13], and for drug delivery using the same mechanism as the biomarkers [14]-[18]. However, where silica falls short, is when biodegradability is desired; if this is the case then silica should not be used, as it is not readily biodegradable.

Several popular polymers used for surface coatings are latex, polystyrene, polyanaline, polypyrrole, and polymethylmethacrylate [19]-[21]. These polymers act similarly to lipids and are easily adaptable to liposomes, bilayer structures that have the same phase on the inside and outside of the barrier. They are often used to as drug delivery vehicles for water soluble drugs due to the stability a bilayer offers. Examples of other types of polymeric material are polyethylene glycol, polypropylene glycol, polyacrylic acid, polycopralactone, and cellulose acetate. These are biodegradable and are better situated to deliver hydrophobic drugs. However, the disadvantages of these materials are that some require an unfriendly organic solvent during fabrication, and it is possible to cause damage to the drug and surrounding tissues. An emulsion is beneficial for drug delivery since its core can be either hydrophobic or hydrophilic. By synthesizing the oil-in-water emulsion with a hydrophobic core, drugs normally insoluble in the body can be dissolved in the core and loaded into the body until they reach their destination. In order to have long-term stability in vivo, the previous studies show silica and polymers have been used to coat the surface. Nonetheless, using these materials for the surface coating of the emulsion should be avoided due to the disadvantages described in the previous sections.

Calcium phosphate coatings have been shown to increase the stability of liposomes in extreme conditions such as low/high pH and UV-exposure [22] [23]. The drawbacks are required dilution of the suspension by 100 fold, which reduces the efficiency, and also an inability to control the thickness of the calcium phosphate shell. In order to increase the stability, while maintaining its primary function as an oxygen carrier, this study created a method of depositing thin layers of calcium phosphate on the emulsion surface. This methodology allows the operator to control the thickness of the coating, while maintaining its oxygen transport capability.

\section{Materials and Method}

\subsection{Materials}

Soy lecithin and perfluorooctyle bromide (PFOB) were respectively purchased from Avanti Polar Lipids, Inc. (Alabaster, AL), and Oakwood Chemical, Inc. (West Columbia, SC). Packed red blood cells (RBC) were obtained from the University Hospital Blood Bank at the University of Utah. The RBC were washed three times with normal saline before being hemolyzed with a hypotonic phosphate buffer. After centrifugation, a supernatant of hemoglobin solution was obtained.

\subsection{Synthesis of the Calcium Phosphate Coated Nanoemulsion}

To synthesize the oil-in-water nanoemulsion, soy lecithin $(1.1 \mathrm{mg} / \mathrm{g})$ was added to PFOB (2 vol\%) and DI water. The sample was stirred at $1200 \mathrm{rpm}$ for $30 \mathrm{~min}$. at room temperature and extruded through the $200 \mathrm{~nm}$ pore size membrane, seven times, at 150 psi. A titration method was utilized to optimize the surface charge of the emulsion with hydrochloric acid ( $\mathrm{HCl}, 0.1 \mathrm{M})$ and to observe the ionic affinity between calcium and phosphate ions on the emulsion surface at $\mathrm{pH} 9$; calcium chloride $\left(\mathrm{CaCl}_{2}, 3.0 \mathrm{mM}, \mathrm{pH} 9\right)$ and phosphate solution $(3.0 \mathrm{mM}, \mathrm{pH}$ 9), from phosphoric acid $\left(\mathrm{H}_{3} \mathrm{PO}_{4}\right)$, were separately titrated into the emulsion suspension. For calcium phosphate coating, the preparation of scheme is in Figure 1. Various calcium phosphate (CaP) coated thicknesses were produced with this alternating layer-by-layer method. First, the emulsion solution was adjusted to $\mathrm{pH} 9$. Then, 


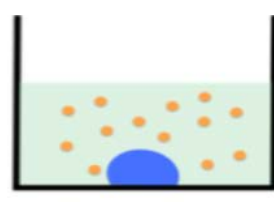

Addition

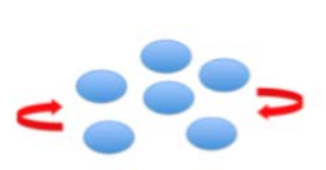

Stirring

Mixing

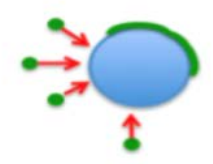

Calcium

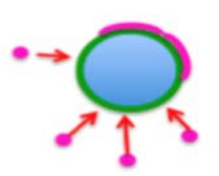

Phosphate

Titration

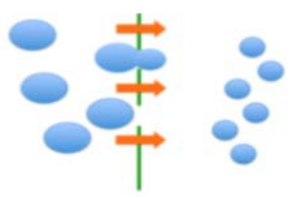

Extrusion

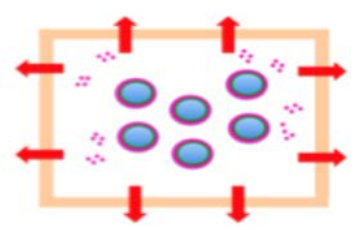

Dialysis

Figure 1. A summary of the synthesis procedure for the calcium phosphate emulsion coating and schematics of the calcium phosphate coated emulsion in layer-by-layer. There are a total of four steps. (1) Addition of the three materials (Lecithin, PFOB, and water) to a beaker in that respective order. Water, PFOB, and Lecithin are respectively represented by light green, blue, and orange. The mixture was stirred at room temperature. (2) The mixture was sized to a uniform particle size ( 280 $\mathrm{nm}$ in diameter). (3) Titration of ions: the first step to coat the emulsion surface. First, calcium chloride (green) was added to the emulsion suspension. Due to the ionic attractive force, calcium ions were adsorbed to the emulsion surface. Next, the suspension had phosphate (pink color) added, and associated with the calcium ions adsorbed to the emulsion surface. (4) The free ions, unassociated ions, were washed away.

the calcium chloride (1.4 mM, pH 9) was titrated to the emulsion with the same volume of the emulsion solution. The phosphate solution (1.4 mM, pH 9) was titrated to the mixture for the next layer of coating with the same volume of the emulsion solution. In each titration, the mixture was adjusted to $\mathrm{pH} 9$. This process was repeated for the desired thicknesses. Once the coating process was completed, the mixture was dialyzed for 3 days against deionized water, with a 3,500 MWCO membrane. After dialysis, the suspension was concentrated back to the original concentration using tangential flow filtration (TFF) (KrosFlo ${ }^{\circledR}$ Research lli Tangential Flow Filtration System, Spectrum Laboratories, Inc., Rancho Dominguez, CA).

\subsection{Characterizations and Stability Test}

The particle size and zeta-potential were characterized by Zetasizer Nano ZS (Malvern, UK). Transmission electron microscope (FEI Tecnai ${ }^{\mathrm{TM}}$ TEM) was utilized for morphology observations, where the emulsion was prepared with a negative stain, uranyl acetate $(47 \mathrm{mM}, 10 \mathrm{uL}$ ). The coated and uncoated emulsions (with and without $\mathrm{CaP}$ ), were observed at $80 \mathrm{keV}$.

\subsection{Rate and Amount of Oxygen Release}

Packed red blood cells (RBCs) were hemolyzed with a hypotonic phosphate buffer (5 mM, pH 7.4) to obtain a hemoglobin solution whose concentration was measured by UV-Vis Spectroscopy. After determining its raw concentration, the solution was adjusted to $120 \mu \mathrm{M}$ and $\mathrm{pH}$ 7.2. Deoxygenated hemoglobin (Hb) was formed by purging the solution with nitrogen gas until the dissolved oxygen probe was reading zero. In order to measure the rate of oxygen release, $\mathrm{Hb}$ and a stopped-flow apparatus (American Instrument Co, Inc, Silver Spring, MY) with a spectrophotometer (Beckman, National Technical Laboratories) were utilized. Four different samples were produced, each with a different number of calcium and phosphate layers. The apparatus was a light-beam path of $4 \mathrm{~mm}$ and the slit $(0.82 \mathrm{~mm})$. The transmittance of the mixture was recorded using LabView software. By monitoring the change of transmittance at $550 \mathrm{~nm}$, $\mathrm{Hb}$ was changed to oxygenated hemoglobin $\left(\mathrm{HbO}_{2}\right)$. The increase of spectra in transmittance at $550 \mathrm{~nm}$ was observed over time at $20^{\circ} \mathrm{C}$ after rapid mixing of the $\mathrm{Hb}$ with the emulsion samples. An average of five successive stopped flow traces were recorded for each sample. The amount of dissolved oxygen was simultaneously determined by the same method as the rate of release. An average of five successive stopped flow traces were recorded for each sample. 


\section{Results and Discussion}

\subsection{Ionic Interaction of the Nanoemulsion}

The $\mathrm{pH}$ titration test clearly supported the notion that the phosphate group in soy lecithin was the main site of ion interaction. Since the amine group in soy lecithin is quaternary, three methyl groups and one R group, it is not $\mathrm{pH}$ active, the phosphate in the head group of soy lecithin was the only group that was expected to react with a proton. The zeta-potential is a good indicator of the dispersion stability. Near zero $\mathrm{mV}$ results in minimal electrostatic repulsion between particles, so the greater absolute value of zeta-potential, the better the stability due to the charge repulsion. From the change in zeta-potential with $\mathrm{pH}$, the isoelectric point (pI) was determined (Figure 2(a) and Figure 2(b)). Soy lecithin molecules are zwitterionic due to the positive quaternary amine and the negative phosphate groups ( $\mathrm{pH}$ dependent), making them ampholytic which means the molecule can obtain equilibrium in either basic or acidic conditions.

A typical emulsion yielded a zeta-potential of $-38.5 \mathrm{mV}$, at $\mathrm{pH} 10.6$, and upon the addition of acid, the zeta-potential continued to increase until it reached $0 \mathrm{mV}$, at $\mathrm{pH} 4.1$, an isoelectric point in good agreement with a previously reported value [24]. At pH values greater than 8.85, the positively charged quaternary amine of soy lecithin is saturated with free $\mathrm{OH}^{-}$ions, making the zeta-potential negative. The addition of more protons drives
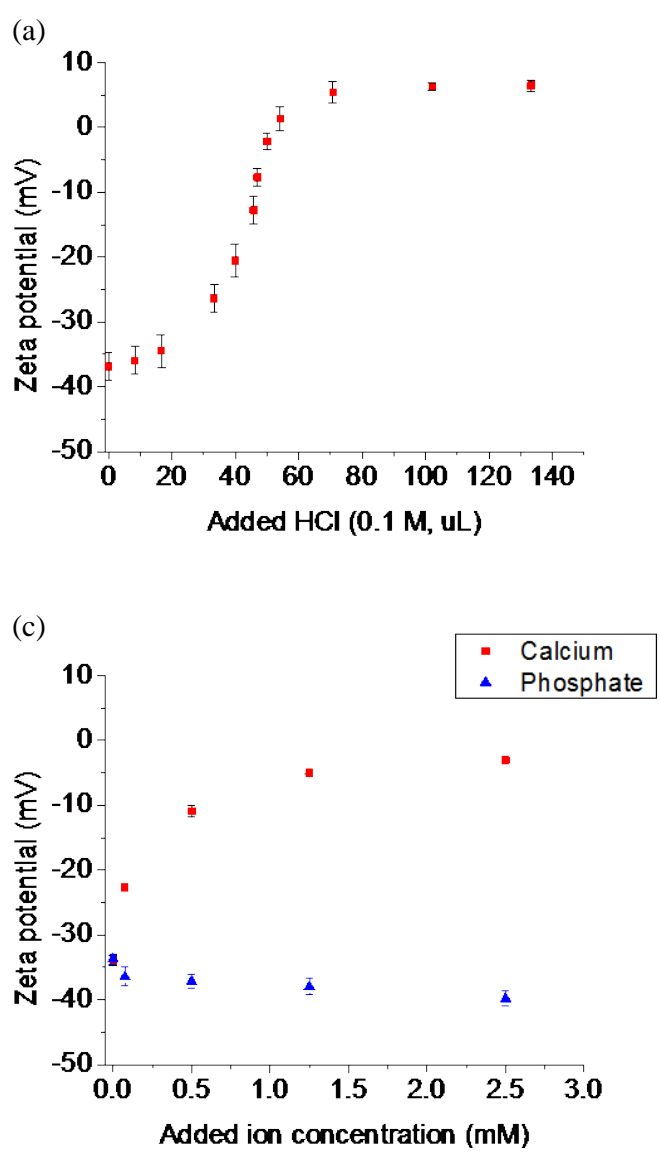

(b)
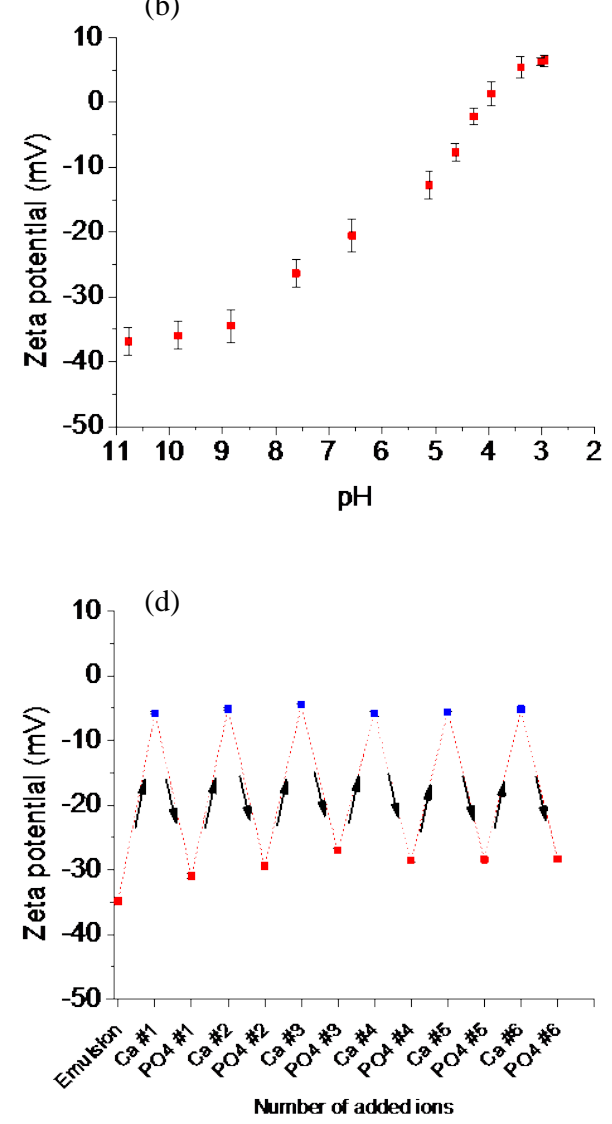

Figure 2. (a) zeta-potential as a function of added $\mathrm{HCl}$ and (b) compiled zeta-potential as a function of pH; the last two data points overlap because both $\mathrm{pH}$ and zeta-potential changed slightly. (c) Ionic affinity of calcium and phosphate to the emulsion surface at $\mathrm{pH}$ 9. Zeta-potential curve of the optimized emulsion at $\mathrm{pH} 9$ with calcium and phosphate ions to find the affinity to the emulsion surface by titration with mean and standard deviation in three measurements. The zeta-potential changed from $-40 \mathrm{mV}$ to $-21 \mathrm{mV}$ by adding calcium, while phosphate changed from $-40 \mathrm{mV}$ to $-46 \mathrm{mV}$. The absolute values of the slope in the first three data points were 18 in calcium and 6 in phosphate. (d) Changes in zeta-potential with the addition of each layer of the calcium phosphate coating. The initial zeta-potential was $-35 \mathrm{mV}$, and the first addition of calcium (Ca) ion increased the potential to $-5 \mathrm{mV}$. Then, the first addition of phosphate $\left(\mathrm{PO}_{4}^{3-}\right)$ decreased the potential to -30 $\mathrm{mV}$. 
the equilibrium reaction, Le Chatelier Principle, toward the production of more water, and as a result there is an increase in zeta-potential. Once the $\mathrm{pH}$ reached the isoelectric point, the overall electric charge of the head group of soy lecithin is neutral. The zeta-potential started to plateau at $\mathrm{pH} 3$, which suggested that all of the phosphate groups had been neutralized with protons, resulting in a net positive charge.

The complexity of the array formed by the soy lecithin molecules made it difficult to tell which of the groups, phosphate or quaternary amine, was actually the primary binding ion site. Complicating matters more is the fact that the head group of the molecule is bent, resting at about $90^{\circ}$ [25]. However, by measuring the zeta-potential through a $\mathrm{pH}$ titration it was concluded that the affinity for free calcium ions toward the soy lecithin phosphate was greater than that of free phosphate ions to the quaternary amine. The zeta-potential demonstrated an isoelectric point at $\mathrm{pH} 5.33$.

\subsection{Ionic Affinity of Calcium and Phosphate}

At $\mathrm{pH} 9$ the emulsion system has its lowest zeta-potential at $-34 \mathrm{mV}$. After the addition of calcium cation, the zeta-potentialincreased to $-3 \mathrm{mV}$, compare this to when phosphate ion ( $\mathrm{HPO}_{4}^{2-}$ ) was added and the zeta-potential only decreased to $-39 \mathrm{mV}$, a change of only $5 \mathrm{mV}$ (Figure 2(c)). At $\mathrm{pH} 9$, the phosphate group is the dominant functional group for soy lecithin because the quaternary amine has been neutralized by the $\mathrm{OH}^{-}$anion. When calcium ions were added to the system, the ion associates itself with the phosphate group due to the lower solubility product constant. The solubility product constant $\left(\mathrm{K}_{\mathrm{sp}}\right)$ values at $25^{\circ} \mathrm{C}$ of calcium hydroxide $\left(\mathrm{Ca}(\mathrm{OH})_{2}\right)$ and calcium hydrogen phosphate $\left(\mathrm{CaHPO}_{4}\right)$ are $5.5 \times 10^{-6}$ and $1 \times 10^{-7}$, respectively [26]; and the lower the solubility, the easier it is precipitates. $\mathrm{CaHPO}_{4}$ has a lower $\mathrm{K}_{\mathrm{sp}}$ value than $\mathrm{Ca}(\mathrm{OH})_{2}$; thus, it is easier for the calcium to bind to the phosphate group than the free hydroxide in solution or those adsorbed to the quaternary amine. Even though soy lecithin has a net neutral charge on its head group, it is still able to bind calcium cations. Building a calcium phosphate shell begins with the addition of calcium ions, followed by a dose of phosphate anions, alternating additions of these two species allowed layer-by-layer buildup of the coating. The deposition of each layer was confirmed with zeta-potential (Figure 2(d)), which showed alternative positive and negative surface charges. The initial zeta-potential of the emulsion was $-34 \mathrm{mV}$, but after the addition of calcium it increased to $-5 \mathrm{mV}$. With the sequential dose of phosphate, the zeta-potential decreased to $-30 \mathrm{mV}$. This same trend continued for each additional layer of calcium and phosphate, confirming the sequential growth process.

\subsection{Calcium Phosphate Coating}

In order to verify the encapsulation of calcium phosphate on the emulsion surface, the particle size was monitored using DLS. With each layer deposited on the emulsion surface the various thicknesses of calcium phosphate are shown in Figure 3. For TEM observation the uncoated emulsion was prepared with a negative stain (Figure 4 (a)), revealing a uniform particle of $227.1 \mathrm{~nm}(+/-128.7 \mathrm{~nm})$, when coated with CaP $(27 \mathrm{mM}$ calcium)

(a)

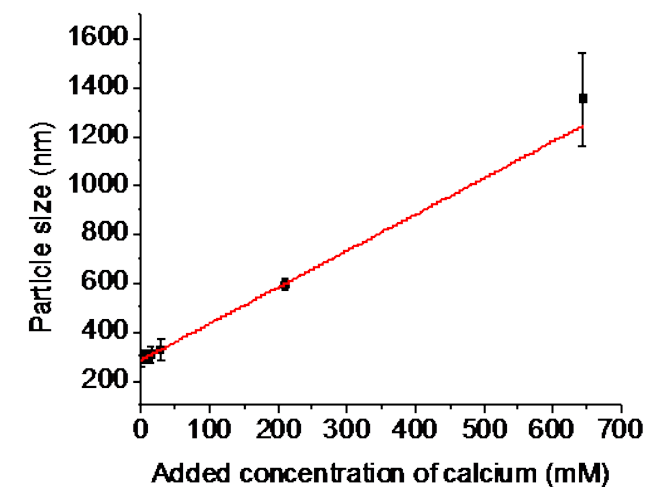

(b)

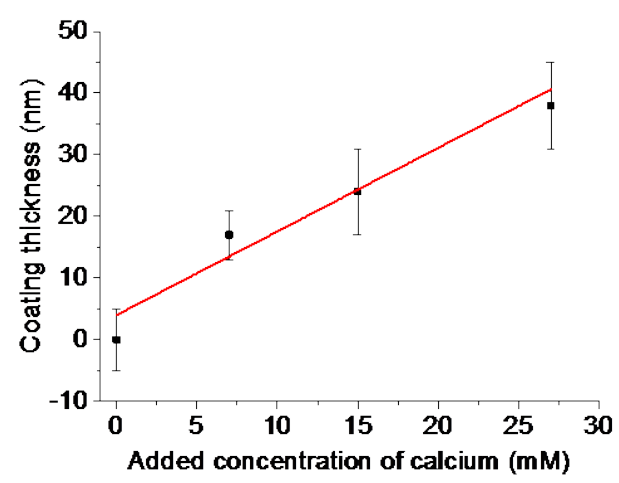

Figure 3. (a) The particle size at various thicknesses of calcium phosphate coating. By constantly adding the calcium phosphate, from 0 to $680 \mathrm{mM}$, the particle size increased from $280 \mathrm{~nm}$ to $1400 \mathrm{~nm}$ in diameter. (b) The coating thickness was calculated by subtracting the particle size from the initial size $(281 \mathrm{~nm})$ from 0 to $27 \mathrm{mM}$. The thickness was increased to 38 $\mathrm{nm}$ in $27 \mathrm{mM}$ of the added calcium ion. 

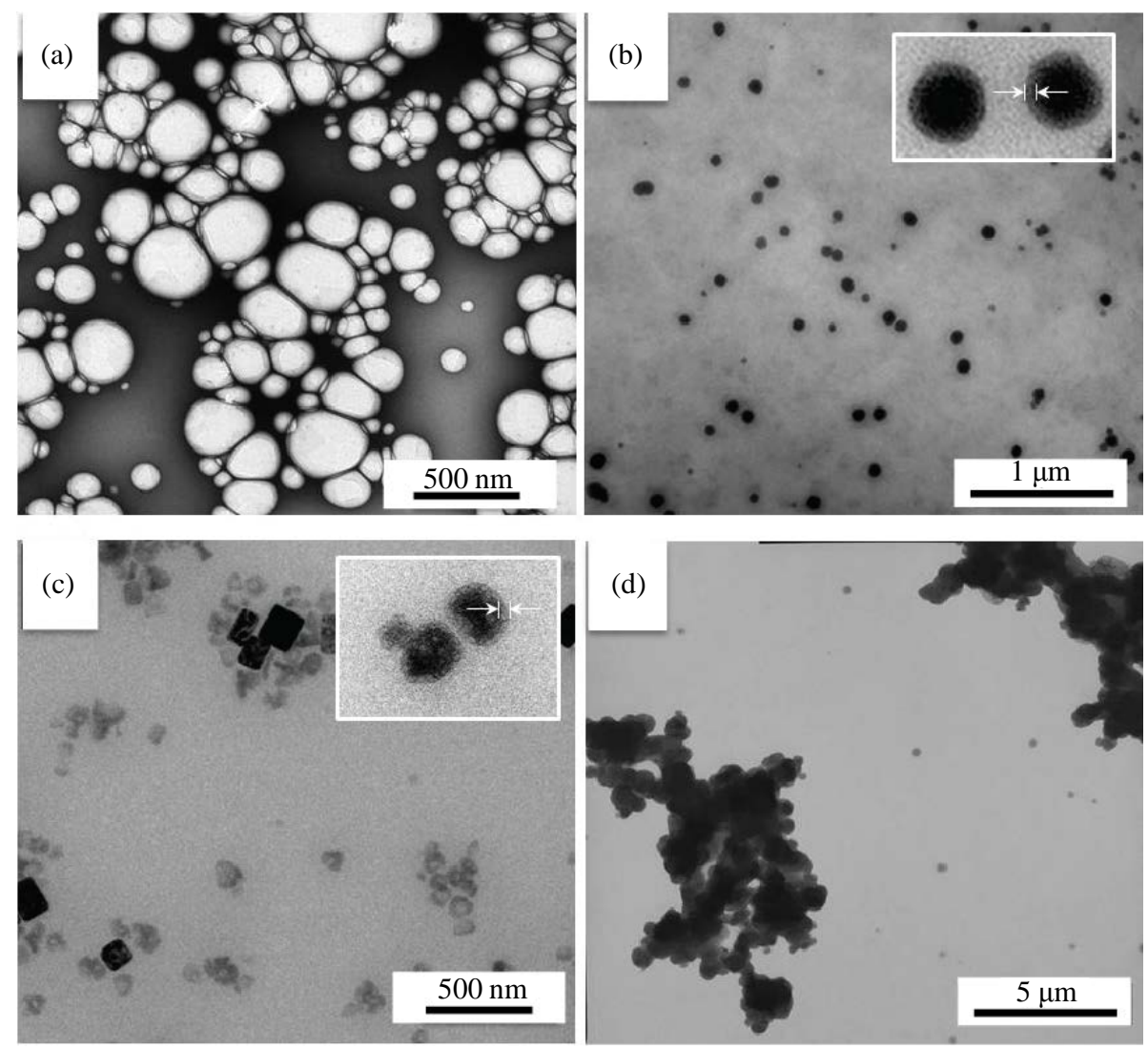

Figure 4. Transmission electron microscopy images of the emulsion and the calcium phosphate (CaP) coated emulsion. (a) The negatively stained emulsion. The emulsion size was $227.1 \mathrm{~nm}(+/-128.7 \mathrm{~nm})$, statistics calculated from 20 particles. (b) The CaP coated emulsion with $14 \mathrm{mM}$ of added calcium and phosphate. The particle size was calculated based on 20 particles with an average of $250.4 \mathrm{~nm}(+/-50.2 \mathrm{~nm})$. The particle has a dark core with a lighter outline, which suggested proper formation of the calcium phosphate shell, with a measured thickness of $11 \mathrm{~nm}(+/-3 \mathrm{~nm})$. This is similar to the value calculated from DLS. (c) The particles formed by adding $40 \mathrm{mM}$ of calcium and phosphate solutions. Once the addition exceeded $30 \mathrm{mM}$, the calcium phosphate crystalline was also formed in the system. There were few emulsion particles, coated with CaP, with an average particle size of $320.7 \mathrm{~nm}(+/-133.6 \mathrm{~nm})$. (d) The addition of calcium and phosphate was $650 \mathrm{mM}$, and all of the particles aggregated. The size of aggregations, measured by dynamic light scattering, was about $1300 \mathrm{~nm}(+/-250$ $\mathrm{nm})$.

the particle grew to $250.4 \mathrm{~nm}(+/-50.2 \mathrm{~nm})$. The micrographs show a dark core with a light shell, a result of the electrons scattering off axis by elastic nuclear interaction known as Rutherford scattering. Darker regions of the micrograph occur due to increased elastic scattering cause by a fixed mean free path, indicative of a thicker coating or higher atomic number elements. The molecular weight of PFOB $\left(\mathrm{C}_{8} \mathrm{~F}_{17} \mathrm{Br}, 498.87 \mathrm{~g} / \mathrm{mol}\right)$ is greater than calcium phosphate $\left(\mathrm{Ca}_{3}\left(\mathrm{PO}_{4}\right)_{2}, 310.18 \mathrm{~g} / \mathrm{mol}\right)$ and brushite $\left(\mathrm{CaHPO}_{4} \cdot 2 \mathrm{H}_{2} \mathrm{O}, 172.09 \mathrm{~g} / \mathrm{mol}\right)$. Therefore, the darker core image (Figure 4(b)) suggested the presence of PFOB, while the lighter area surrounding the particle was defined as the calcium phosphate shell. When the calcium phosphate thickness was increased in Figures 4(c) and Figure 4(d), by adding calcium $(220 \mathrm{mM})$, calcium phosphate crystalline began to form on the emulsion, and at $600 \mathrm{mM}$, aggregation of the particles became apparent. Greater addition of CaP layers resulted in a greater particle size. This is a result of the aggregation that is likely to occur while the samples dry on the TEM grid.

\subsection{Rate and Amount of Oxygen Release}

The relationship between the thickness of the coating and amount of oxygen released was studied and the results showed an increase in coating thickness which caused the amount of oxygen released to drop from $77 \mu \mathrm{M}$ to 45 $\mu \mathrm{M}$, and the kinetic constant $\left(\mathrm{k}_{1}\right)$ decreased from $2.8 \mathrm{~s}^{-1}$ to $0.6 \mathrm{~s}^{-1}$ (see Figure 5). The mass transport pathway starts with the soy lecithin monolayer, after which, the oxygen must travel through the calcium phosphate shell. 

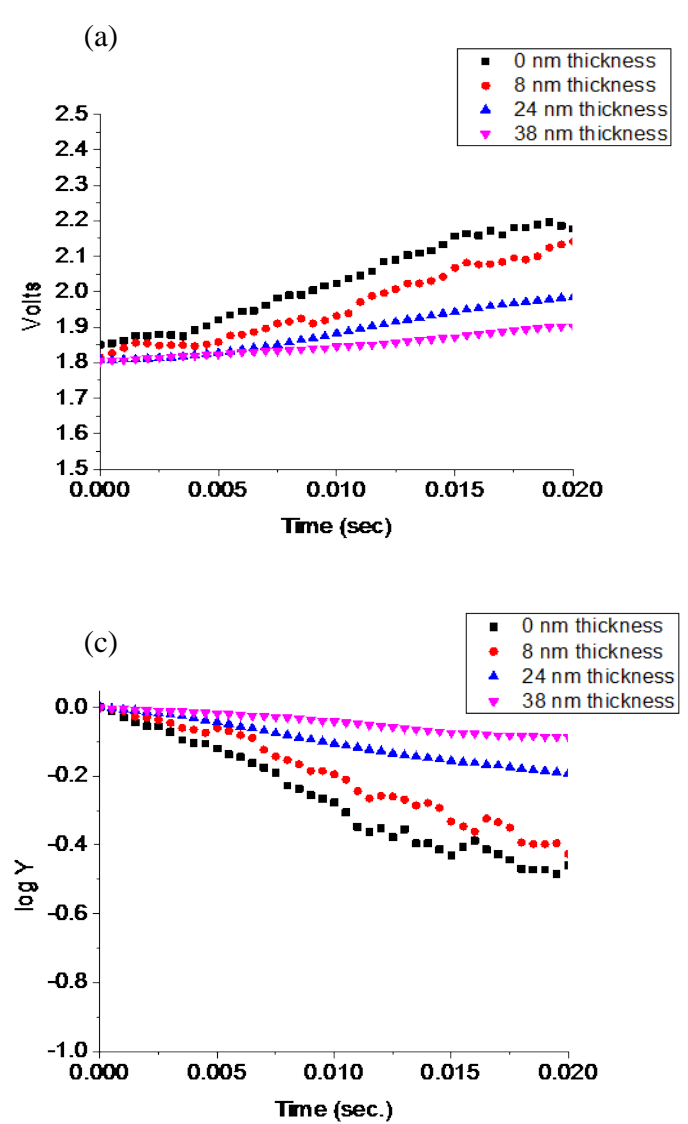

(b)

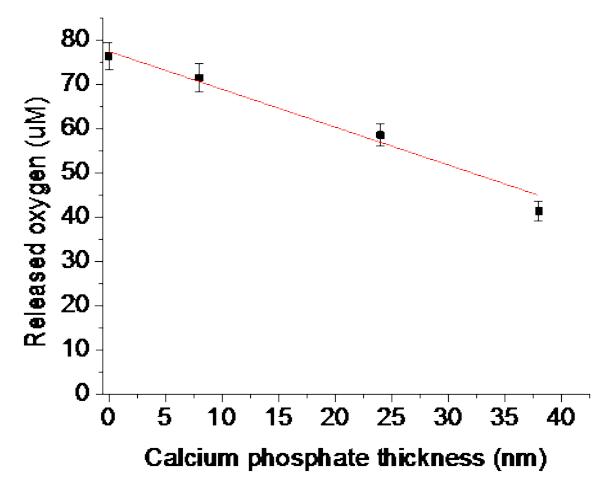

(d)

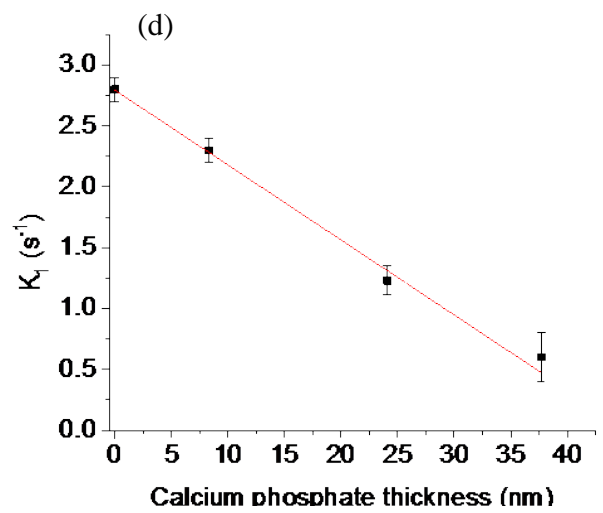

Figure 5. The oxygen capacity and release rate from emulsion particles. (a) The oscilloscope trace of transmittance in volts versus time for the $\mathrm{Hb}$ and the calcium phosphate coated emulsion at $\mathrm{pH}$ 7.2. With increasing coating thickness, the $\mathrm{Hb}$ was less saturated with oxygen. (b) The oxygen uptake by $\mathrm{Hb}$ at various coating thickness with the mean and standard deviation taken from five measurements. The transmittance voltage was converted to molar concentration of oxygen uptake by hemoglobin. (c) The logarithm of the absorbance versus time for the $\mathrm{Hb}$ and $\mathrm{CaP}$ emulsion. (d) The first order kinetic constant of the oxygen uptake by $\mathrm{Hb}$ with the mean and standard deviation taken from five measurements. Increasing the coating layer thickness slowed, and reduced, the amount of oxygen absorbed by hemoglobin.

The total length of the Soy Lecithin molecule, including head group and tail, is $5.03 \mathrm{~nm}$ [27], and the thickness of the calcium phosphate coating varied between 8 to $38 \mathrm{~nm}$. It was expected that the diffusion time for the coated emulsion would be significantly longer than that of the uncoated particle due to the extra barrier. Even though hemoglobin has four positions to which oxygen can associate itself, this study was only concerned with the kinetics of the first oxygen to bind to the $\mathrm{Hb}$ because the other three are non-linearly related to each other with respect to time. Therefore, a pseudo first-order reaction was assumed, Equation 1, and it was used to calculate the first order kinetics rate coefficient $\left(\mathrm{k}_{\mathrm{a}_{1}}\right)$.

$$
\begin{aligned}
\frac{\mathrm{d}\left[\mathrm{HbO}_{2}\right]}{\mathrm{dt}} & =-\mathrm{k}_{\mathrm{a}}\left[\mathrm{HbO}_{2}\right] \\
\log \mathrm{Y} & =-2.3 \mathrm{k}_{\mathrm{a}_{1}} \mathrm{t}
\end{aligned}
$$

where $\left[\mathrm{HbO}_{2}\right]$ was the concentration of the oxygenated $\mathrm{Hb}$, $\mathrm{t}$ was the time for the first binding reaction, and $\mathrm{Y}$ was the fraction of hemoglobin absorbance at $550 \mathrm{~nm}$. By plotting the logarithm of $\mathrm{Y}$ as a function of time, $\mathrm{k}_{\mathrm{a}_{1}}$ was obtained from the slope. According to this relation, $\mathrm{k}_{\mathrm{a}_{1}}$ showed a lower value with a thicker coating, which confirmed the idea that the coating thickness controlled the release oxygen. The amount of oxygen inside the coated particle was less than the uncoated emulsion; hence, the oxygen uptake by Hb was lower than the uncoated emulsion. In order to verify the final oxygen content in the samples the reaction was continuously monitored until the transmittance level plateaued. The thicker calcium phosphate coating resulted in a longer diffu- 
sion time of oxygen across the interface

\section{Conclusion}

In summary, the three objectives of this study were to size the emulsion particle to a desired diameter, to coat the sized particle with calcium phosphate, and to determine the stability and the oxygen release/content. The emulsion mixture was unable to naturally form uniform, dispersed particles, so it was extruded through a polymer membrane under constant pressure. The emulsion was pushed through the membrane seven times in order to ensure that the particles were uniform and dispersed. The result was a reduction in size from 1 um to $280 \mathrm{~nm}$ in diameter. The uniform size and dispersion of the particles were essential for the coating procedures that followed. In order to ensure the optimal dispersion of particles, the zeta-potential was monitored as a function of $\mathrm{pH}$, since some type of surface charge was necessary to avoid flocculation, coalescence, or creaming. The optimal dispersion was found to be at $\mathrm{pH} 8.8$, where a strong negative charge encapsulated the particles. The change in zeta-potential was 32 times greater with calcium than with phosphate, indicating that the soy lecithin molecule had a higher affinity for positively charged calcium over the negative phosphate. The binding coefficient of the calcium ion to soy lecithin was studied, using a Hill Plot, to estimate the amount of the calcium that would be needed for a full coating. The results showed binding of one calcium ion to one soy lecithin molecule. In order to verify the layer-by-layer growth, zeta-potential was used to monitor changes in surface charge. When the calcium ion was added to the emulsion system, the potential increased, and it returned to its initial value when the phosphate ion was added. Using these monitoring techniques, the emulsion particles were coated with calcium phosphate to various thicknesses ranging from $8 \mathrm{~nm}$ to $38 \mathrm{~nm}$. Using a fast mixing method, with a stopped-flow apparatus and hemoglobin, oxygen release/content of the coated emulsion was measured. Combining these tools, the oxygen from the particle was measured quickly and accurately. When the thickness of the coating on the emulsion particle was increased, the amount of oxygen released over a given time decreased from $77 \mu \mathrm{M}$ to $45 \mu \mathrm{M}$.

\section{Acknowledgements}

The authors would like to thank A. Ostafin and H. Mizukami for support and comments. Furthermore, the authors acknowledge the contributions of collaborators, C. Wu and C. Takagi. This work is supported by Nanoshell Co. (Layton, UT) and NSF-IGERT program; 0903715.

\section{References}

[1] Vásquez, D., Ortiz, D., Alvarez, O., Briceño, J. and Cabrales, P. (2013) Hemorheological Implications of Perfluorocarbon Based Oxygen Carrier Interaction with Colloid Plasma Expanders and Blood. Biotechnology Progress, 29, 796807. http://dx.doi.org/10.1002/btpr.1724

[2] Filho, I., Pedro, J., Narayanan, S., Nguyen, N., Roseff, S. and Spiess, B. (2013) Perfluorocarbon Emulsion Improves Oxygen Transport of Normal and Sickle Cell Human Blood in Vitro. Journal of Biomedical Materials Research Part A, 102, 2105-2115. http://dx.doi.org/10.1002/jbm.a.34885

[3] Modery-Pawlowski, C., Tian, L., Pan, V. and Gupta, S. (2013) Synthetic Approaches to RBC Mimicry and Oxygen Carrier Systems. Biomacromolecules, 14, 939-948. http://dx.doi.org/10.1021/bm400074t

[4] Sakai, H., Sou, K., Horinouchi, H., Tsuchida, E. and Kobayashi, K. (2012) Removal of Cellular-Type Hemoglobin-Based Oxygen Carrier (Hemoglobin-Vesicles) From Blood Using Centrifugation and Ultrafiltration. Artificial Organs, 36, 202-209. http://dx.doi.org/10.1111/j.1525-1594.2011.01236.X

[5] Xiong, Y., Steffen, A., Andreas, K., Muller, S., Sternberg, N., Georgieva, R., et al. (2012) Hemoglobin-Based Oxygen Carrier Microparticles: Synthesis, Properties, and in Vitro and in Vivo Investigations. Biomacromolecules, 13, 32923300. http://dx.doi.org/10.1021/bm301085x

[6] Liu, M., Gan, L., Chen, L., Zhu, D., Xu, Z., Hao, Z., et al. (2012) A Novel Liposome-Encapsulated Hemoglobin/Silica Nanoparticle as an Oxygen Carrier. International Journal of Pharmaceutics, 427, 354-357. http://dx.doi.org/10.1016/j.ijpharm.2012.02.019

[7] Patarin, J., Lebeau, B. and Zana, R. (2002) Recent Advances in the Formation Mechanisms of Organized Mesoporous Materials. Current Opinion in Colloid \& Interface Science, 7, 107-115. http://dx.doi.org/10.1016/s1359-0294(02)00012-2

[8] Radloff, C. and Halas, N. (2001) Enhanced Thermal Stability of Silica-Encapsulated Metal Nanoshells. Applied Phys- 
ics Letters, 79, 674. http://dx.doi.org/10.1063/1.1389322

[9] Akbarian, F., Lin, A., Dunn, B., Valentine, J. and Zink, J. (1997) Spectroscopic Determination of Cholinesterase Activity and Inhibition in Sol-Gel Media. Journal of Sol-Gel Science and Technology, 8, 1067-1070.

[10] Rioux, R., Song, H., Hoefelmeyer, J., Yang, P. and Somorjai, G. (2005) High-Surface-Area Catalyst Design: Synthesis, Characterization, and Reaction Studies of Platinum Nanoparticles in Mesoporous SBA-15 Silica. The Journal of Physical Chemistry B, 109, 2192-2202. http://dx.doi.org/10.1021/jp048867x

[11] Lang, H. and Chandler, B. (2004) Silica Supported Bimetallic Platinum-Gold Nanoparticle Catalysts from Dendrimer Mediated Route. Abstracts of Papers of the American Chemical Society, 228.

[12] Santra, S., Dutta, D. and Moudgil, B. (2005) Functional Dye-Doped Silica Nanoparticles for Bioimaging, Diagnostics and Therapeutics. Food and Bioproducts Processing, 83, 136-140.

[13] Scott, B., Wirnsberger, G. and Stucky, G. (2001) Mesoporous and Mesostructured Materials for Optical Applications. Chemistry of Materials, 13, 3140-3150. http://dx.doi.org/10.1021/cm0110730

[14] Bharali, D., Klejbor, I., Stachowiak, E., Dutta, P., Roy, I., Kaur, N., et al. (2005) Organically Modified Silica Nanoparticles: A Nonviral Vector for in Vivo Gene Delivery and Expression in the Brain. Proceedings of the National Academy of Sciences, 102, 11539-11544.

[15] Kumar, M., Smati, M., Mohapatra, S., Kong, X., Lockey, R., Bakowsky, U., et al. (2004) Cationic Silica Nanoparticles as Gene Carriers: Synthesis, Characterization and Transfection Efficiency in Vitro and in Vivo. Journal of Nanoscience and Nanotechnology, 4, 876-881.

[16] Yang, H., Zhang, S., Chen, X., Zhuang, Z., Xu, J. and Wang, X. (2004) Magnetite-Containing Spherical Silica Nanoparticles for Biocatalysis and Bioseparations. Analytical Chemistry, 76, 1316-1321. http://dx.doi.org/10.1021/ac034920m

[17] Itoh, Y., Matsusaki, M., Kida, T. and Askashi, M. (2004) Preparation of Biodegradable Hollow Nanocapsules by Silica Template Method. Chemistry Letters, 33, 1552-1553. http://dx.doi.org/10.1246/cl.2004.1552

[18] Naik, R., Tomczak, M., Luckarift, H., Spain, J. and Stone, M. (2004) Entrapment of Enzymes and Nanoparticles Using Biomimetically Synthesized Silica. Chemical Communications, No. 15, 1684-1685. http://dx.doi.org/10.1039/b404586f

[19] Tong, X., Tang, T., Zhu, N., Feng, Z. and Huang, B. (2002) Preparation of Polymer/Silica Nanoscale Hybrids through Sol-Gel Method Involving Emulsion Polymers ( $\left.\mathrm{PMMA} / \mathrm{SiO}_{2}\right)$. Chemical Journal of Chinese Universities-Chinese, 23, 306-309.

[20] Wu, M., O’Neil, S., Brousseau, L., McConnell, W., Shultz, D., Linderman, R., et al. (2000) Synthesis of NanometerSized Hollow Polymer Capsules from Alkanethiol-Coated Gold Particles. Chemical Communications, No. 9, 775-776. http://dx.doi.org/10.1039/b001019g

[21] Fleming, M., Mandal, T. and Walt, D. (2001) Nanosphere-Microsphere Assembly: Methods for Core-Shell Materials Preparation. Chemistry of Materials, 13, 2210-2216. http://dx.doi.org/10.1021/cm010168z

[22] Schmidt, H. and Ostafin, A. (2002) Liposome Directed Growth of Calcium Phosphate Nanoshells. Advanced Materials, 14, 532-535. http://dx.doi.org/10.1002/1521-4095(20020404)14:7<532::AID-ADMA532>3.0.CO;2-4

[23] Schmidt, H., Gray, B., Wingert, P. and Ostafin, A. (2004) Assembly of Aqueous-Cored Calcium Phosphate Nanoparticles for Drug Delivery. Chemistry of Materials, 16, 4942-4947. http://dx.doi.org/10.1021/cm040056i

[24] Liu, A. (2006) Acid-Base Equilibria between the Lipid Membrane and Electrolyte Solution. Elsevier, San Diego.

[25] Pullman, A., Jortner, J. and Pullman, B. (1994) Biomolecular Structures and Mechanism. Kluwer Academic Publishers, Dordrecht.

[26] Benesch, R., Benesch, R., Renthal, R. and Maeda, N. (1972) Affinity Labeling of the Polyphosphate Binding Site of Hemoglobin. Biochemistry, 11, 3576-3582. http://dx.doi.org/10.1021/bi00769a013

[27] Roy, B., Fazal, M., Arruda, A., Malik, S. and Campiglia, A. (2000) Polymerized Fluorescent Liposomes Incorporating Lanthanide Ions. Organic Letters, 2, 3067-3070. http://dx.doi.org/10.1021/ol006357p 